\title{
QUEEN'S
UNIVERSITY
BELFAST
}

\section{Burden of vision loss associated with eye disease in China 1990-2020: findings from the Global Burden of Disease Study 2015}

Wang, B., Congdon, N., Bourne, R. R., Li, Y., Cao, K., Zhao, A., yusufu, M., Dong, W., Zhou, M., \& Wang, N. (2017). Burden of vision loss associated with eye disease in China 1990-2020: findings from the Global Burden of Disease Study 2015. British Journal of Ophthalmology. https://doi.org/10.1136/bjophthalmol-2017-310333

Published in:

British Journal of Ophthalmology

Document Version:

Peer reviewed version

Queen's University Belfast - Research Portal:

Link to publication record in Queen's University Belfast Research Portal

Publisher rights

Copyright 2017 Wang et al.

This work is made available online in accordance with the publisher's policies. Please refer to any applicable terms of use of the publisher.

\section{General rights}

Copyright for the publications made accessible via the Queen's University Belfast Research Portal is retained by the author(s) and / or other copyright owners and it is a condition of accessing these publications that users recognise and abide by the legal requirements associated with these rights.

Take down policy

The Research Portal is Queen's institutional repository that provides access to Queen's research output. Every effort has been made to ensure that content in the Research Portal does not infringe any person's rights, or applicable UK laws. If you discover content in the Research Portal that you believe breaches copyright or violates any law, please contact openaccess@qub.ac.uk. 
Burden of vision loss associated with eye diseases in China 1990-2020: Findings from the Global Burden of Disease Study 2015

Bingsong Wang, PhD, 1,2 Rupert Bourne, MD, ${ }^{3}$ Kai Cao, ${ }^{1}$ Yichong Li, ${ }^{4}$ Aiping Zhao, ${ }^{1}$ Mayinuer Yusufu, ${ }^{1}$ Wenlan Dong, ${ }^{4}$ Maigeng Zhou, PhD, ${ }^{4}$ Nathan Congdon,,${ }^{5,6}$ Ningli Wang, PhD, ${ }^{1,2}$

1 Beijing Institute of Ophthalmology, Beijing, China;

2 Beijing Tongren Hospital, Capital Medical University, Beijing, China;

3 Vision and Eye Research Unit, Postgraduate Medical Institute, Anglia Ruskin University, Cambridge;

4 National Center for Chronic and Non-communicable Disease Control and Prevention, Chinese Center for Disease Control and Prevention, Beijing, China;

5 Centre for Public Health, Queen's University Belfast, Belfast UK;

6. Zhongshan Ophthalmic Center, Sun Yat-sen University, Guangzhou, China

Correspondence to:

Prof Ningli Wang, Beijing Tongren Eye Center, Beijing Tongren Hospital, Capital Medical University, Beijing, China; Beijing Institute of Ophthalmology, Beijing, China. No. 1 Dong Jiao Min Xiang Street, Dongcheng District, Beijing, People's Republic of China.

Email: wningli@vip.163.com

Prof Nathan Congdon, Centre for Public Health, Queen's University Belfast, Belfast UK; Zhongshan Ophthalmic Center, Sun Yat-sen University, Guangzhou, China.

Email: ncongdon1@gmail.com

Commented [NC1]: Please add my affiliation with Orbis:

Orbis International, New York, USA. 


\section{Abstract}

Aims TOur study aimed to assess-and analyze the burden of vision loss due to eye diseases in China between 1990 and 2015, and-alse to predict the burden in 2020.

Methods Data from the Global Burden of Diseases, Injuries, and Risk Factors Study 2015 (GBD 2015) were used. The main outcome measureements were pPrevalence and Years lived with disability (YLDs)_. The Number, Rate and Percentage in Prevalence and YLDs-for vision loss due to Cataract, Glaucoma, Macular degeneration, Other vision loss, Refraction and accommodation disorders Refractive error and Trachoma-were computed and analyzed.

Results Prevalences for theseall the eye diseases increasedhave been increasing steadily from 1990 to 2015, and will increase till 2020. From 1990 to 2015, the most commonleading eye disorder was Refraction and accommodation disorders. Comparinged with those in 1990 the proportion of the total vision loss burden due to eye disease among those under the age of 14 years in 2015 decreased under the age of 14 years, increased $\underline{\text { while that }}$ above the age of 15 years increased, especially increased substantiallymost prominently above the age of 50 years. China ranked $10^{\text {th }}$ when comparing YLDs for vision loss due to eye diseases in China with that of the the other 18 member countries-members of the G20.-(the 20th member is the European Union). Age-standardized YLD Rates for vision loss due to eye diseases declined in the other all the 19 countries, except for that in-China. The bBurden from vision loss due to eye diseases ranked $12^{\text {th }}$ and $11^{\text {th }}$ among all the-causes ofthat can lead to health loss in China in 1990 and 2015 respectively.

Conclusion Alone among major economies, For the past 25 years, China has experiencedhad less control over the vision loss burden from an increase in the burden of age-standardized vision loss from eye disease over the last two decadess. In the future, China maywill expect a growinglarger burden of vision loss due tobecause of population growth and ageing.

Funding Ministry of Health of the Ppeople's Rrepublic of China (Grant Number 201002019). 
China has the world's largest population, over 1.406 billion, accounting for nearly $20 \%$ of the earth's inhabitants. ${ }^{1}$ China has made enormous strides in improving health in the past few decades: life expectancy at birth has steadily increased and the under- 5 mortality rate has greatly fallen sharply. ${ }^{2-4}$ At the same time, more needs to be done to further enhance the quality of the longer lives of China's citizens. A comprehensive assessment of current and expected disease burdens can help to inform China's health reform efforts, and provide evidence to support long-range strategies.

Vision loss due to eye diseases is a major health problem, greatly affecting quality of life. Globally as of $2015,34 \cdot 3$ million people weare blind, an additional $24 \cdot 3$ million hdave severe vision impairment, 214 million hadave moderate vision impairment, and 663 million hadve near vision impairment in $2015 .{ }^{5}$ Vision loss is the third largest cause of impairment after anaemia and hearing loss ${ }_{-}{ }^{6}$ but t the burden of vision loss in China remainsis still_- unclearyet. The GGlobal Burden of Diseases Study is the result of a worldwide collaboration aimed at quantifying various health metrics of loss to diseases and injuries. These metrics enable comparison of health data across boundaries of geography and time in a way that is more comprehensive and internally consistent than possible with previous data sources. ${ }^{6-8}$

Our study aimsed to quantify the burden of vision loss due to various eye diseases in China from 1990 to 2015 using the Global Burden of Diseases, Injuries, and Risk Factors Study 2015 (GBD 2015), and also to predict the burden in 2020. 
Data from the Global Burden of Diseases, Injuries, and Risk Factors Study 2015 (GBD 2015) from 1990 to 2015 were used to analyze the burden of vision loss due to eye diseases in China. ${ }^{7}$ We searched and extracted related data from a website database (http://ghdx.healthdata.org), which was set up and shared by the Global Burden of Disease Study group. Details on the data, approaches to enhancing data quality and comparability, and statistical modeling and metrics for the GBD 2015 have been reported previously. ${ }^{6-9}$ In brief, the GBD study team collected data from household surveys archived in the Global Health Data Exchange, sources suggested by in-country experts, and surveys identified in major multinational survey data catalogues and Ministry of Health and Central Statistical Office websites. Then they estimated incidence and prevalence of various conditions by age, sex, cause, year, and geography using a wide range of updatand-standardised analytical procedures, including s. The procedure includes several steps such as data screening, data adjustment, DisMod-MR 2.1 estimation, and injury modelling strategies.y, and so on. Then ŁThe GBD investigatorsstudy used numerous metrics to report results on health loss related to specific causes of disease and injury: deaths and death rates, years of life lost due to premature mortality (YLLs), years lived with disability (YLDs), and disability-adjusted life-years (DALYs). 2,9

The main outcome measure of our study were pPrevalence and YLDs, and the Numbers, Rates and Percentages of Prevalence and YLDs forassociated with the vision loss burden due to various eye diseases aseressed and analyzed. YLDs refer to years of life lived with any short-term or long-term health loss, which were equal to the prevalence of the eye disease multiplied by its associated disability weights. ${ }^{10} \mathrm{GBD} 2013$ included new data for disability weights, which quantify the severity of health loss associated with a particular disease. ${ }^{8}$ Disability weights uses numbers on a scale from 0 to 1 that represents the severity of health loss associated with a particular health state. 8,10-12 The severity of health loss was based on surveys of the general public in five countries (Bangladesh, Indonesia, Peru, Tanzania, and the USA) and an open internet survey. 8,10-12 These disability weights were used to calculate the YLDs for various diseases. The YLD Rates were calculated by dividing the number of years of life lost by the relevant population. ${ }^{10-12}$ The-Age-adjusted Rates were calculated using the WHO 2000-2025 World standard population, which excluded the effects of total population size and age structure.8,9,12 The Percentage fors in YLDs were calculated as the number of years lived with disabilitylost due to a specific disease divided by the total number of years lived with disability-of life lost for all diseases.

The following six ocular diseases were listed in the GBD 2015: Cataract, Glaucoma, Macular degeneration, Trachoma, Refraction and accommodation disorders and Other vision loss. ${ }^{7}$ The other vision loss category included a total of 57 eye conditions. ${ }^{13}$ The changing trends of the burden of vision loss over time and with age were investigated. We also compared the burden of vision loss in China with the burden of other diseases and with the burden of vision loss in other countries. 
Results

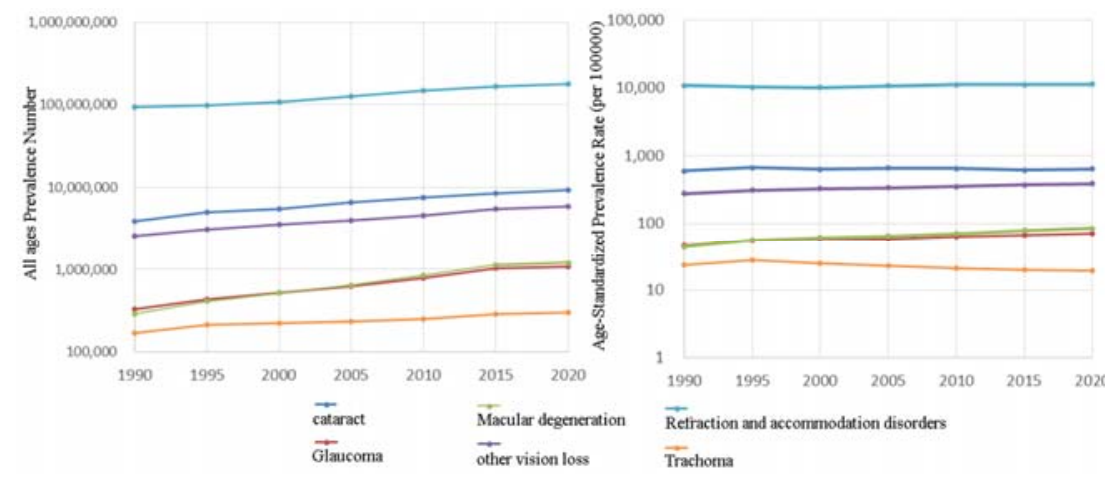

Figure 1: Prevalence for various eye diseases from 1990 to 2020 in China.

From 1990 to 2015, the most commonteading eye disorder in China was Refraction and accommodation disorders whose prevalences were much higher than these of other eyediseases-(fFigure 1)-, while-T the second most commonleading cause was Cataract, followed by Other vision loss. Prevalences for Macular degeneration and Glaucoma were similar, with Glaucoma being more common-a bit more before 2005 and Macular degeneration being a bit more common after 2005. The pPrevalences for Trachoma was the lowest. Prevalences for all includedthe eye diseases have been increasing steadily from 1990 to 2015, and willare projected to increaserise untiltill 2020. We further analyzed Age-standardized Pprevalence Rrates. Prevalence Rates for Refraction and accommodation disorders, Cataract and Other vision loss almostremained essentially unchanged, w. While__Prevalence Rrates for Macular degeneration and Glaucoma increased slightly-slightly went up and those for Trachoma fell considerablygreatly went down. 


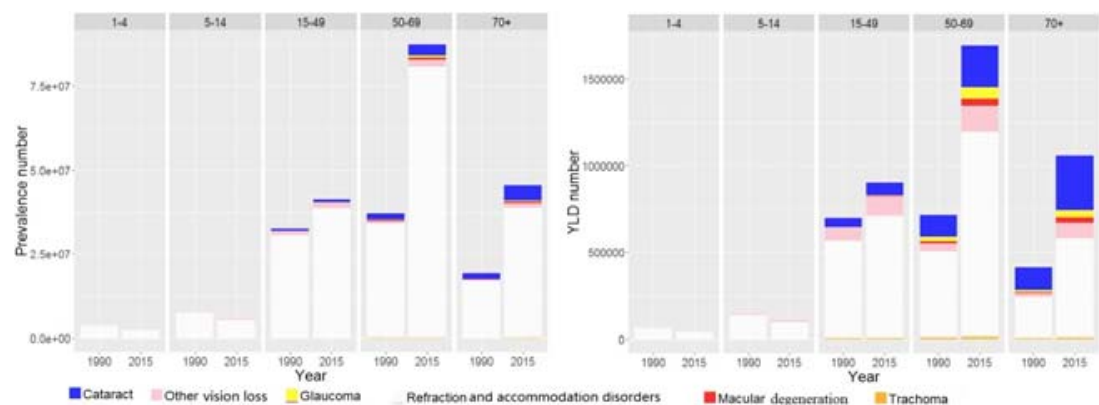

YLDs: years lived with disability

Figure 2: Distribution of pPrevalence for various eye diseases and YLDs from vision loss due to eye diseases in China, by age, 1990 and 2015 (figure left: Prevalence; figure right: YLDs)

Comparing with those in 1990, the proportion of the totalThe -vision loss burden due to eye disease in 2015 decreased between 1990 and 2015 for those under the age of 14 years, and increased among those above the age of 15 years and above, with the most notable especially increased substantially increases occurring atabove the age of 50 years and above (Efigure 2). The bAbove the age of 50 years, burden of vision loss due to every individual eye disease, which included Cataract, Glaucoma, Macular degeneration, Trachoma, Refractionand accommodation disorders and Other vision loss, increased from 1990 to 2015 among those 50 and above, Twith the relative contributions of individual eye diseases to the overall burden changeingd little over this time-between 1990 and 2015. There was lack of data on vision burden from Cataract and Glaucoma in the 0 to 14 age range. Refraction and accommodation disorders accounted for the majority of the burden of vision loss in all age groups both in 1990 and in 2015. 


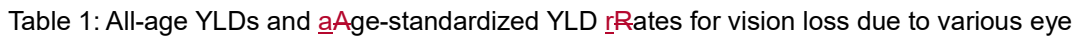
diseases in 1990 and 2015 for 19 member countries of the Group of $20 \mathrm{G} 20$ (The $20^{\text {th }}$ member is the European Union)

\begin{tabular}{|c|c|c|c|c|c|c|}
\hline \multirow[t]{2}{*}{ Country name } & \multirow{2}{*}{$\begin{array}{l}\text { All-age YLDs } \\
\text { Total Number in } \\
1990\end{array}$} & \multicolumn{2}{|c|}{ All-age YLDs in 2015} & \multirow{2}{*}{$\begin{array}{c}\text { Age- } \\
\text { standardised } \\
\text { YLD Rate in } \\
1990 \\
\text { (per } 100000)\end{array}$} & \multicolumn{2}{|c|}{$\begin{array}{c}\text { Age- } \\
\text { standardised } \\
\text { YLD in } 2015\end{array}$} \\
\hline & & TotalNumber & Rank & & $\begin{array}{c}\text { Rate } \\
\text { (per } 100000 \text { ) }\end{array}$ & Rank \\
\hline Argentina & 60599.8 & 83408.9 & 16 & 200.2 & 184.3 & 13 \\
\hline Australia & 25155.6 & 40733.2 & 19 & 144.1 & 137.9 & 15 \\
\hline Brazil & 304261.5 & 571429.5 & 5 & 304.6 & 295.4 & 8 \\
\hline Canada & 32291.3 & 50606.0 & 18 & 112.5 & 111.4 & 19 \\
\hline China & 2047612.3 & 3800391.3 & 2 & 241.4 & 257.8 & 10 \\
\hline France & 96785.4 & 127394.3 & 14 & 143.2 & 134.4 & 16 \\
\hline Germany & 162720.4 & 198186.4 & 10 & 164.1 & 152.9 & 14 \\
\hline India & 2977270.0 & 5358196.6 & 1 & 574.4 & 539.0 & 1 \\
\hline Indonesia & 451601.8 & 700590.1 & 3 & 416.1 & 368.1 & 5 \\
\hline Italy & 143658.6 & 192572.7 & 11 & 207.3 & 193.9 & 12 \\
\hline Japan & 364310.7 & 566869.1 & 6 & 268.8 & 261.3 & 9 \\
\hline Mexico & 218669.0 & 424234.9 & 8 & 405.3 & 405.1 & 3 \\
\hline Russia & 507649.4 & 615370.6 & 4 & 327.9 & 317.0 & 6 \\
\hline Saudi Arabia & 38520.6 & 78733.8 & 17 & 420.4 & 371.0 & 4 \\
\hline South Africa & 106195.5 & 176087.8 & 12 & 430.5 & 420.7 & 2 \\
\hline South Korea & 90642.7 & 150444.5 & 13 & 267.9 & 254.0 & 11 \\
\hline Turkey & 137962.9 & 223080.6 & 9 & 348.7 & 314.8 & 7 \\
\hline $\begin{array}{l}\text { United } \\
\text { Kingdom }\end{array}$ & 99078.5 & 114855.4 & 15 & 142.2 & 132.7 & 17 \\
\hline United States & 313948.2 & 444171.7 & 7 & 116.5 & 115.0 & 18 \\
\hline
\end{tabular}

YLDs: years lived with disability

We compared YLDs for vision loss due to eye diseases in China with that of the other 18 member countries of the $\mathrm{G} 20$ (the 20th member is the European Union) (tTable 1). We found that, comparing with that in 1990, aAAll-age YLDs for the burden of vision loss in 2015_ increased in all the 19 countries between 1990 and 2015 in different degrees. In 2015 China ranked $2^{\text {nd }}$ for aAll-age YLDs, only-behind only India. In terms of the aAge-standardized YLD rRates for vision loss burden, China ranked $10^{\text {th }}$, , behind India, South Africa, Mexico, SaudiArabia, Indonesia, Russia, Turkey, and Brazil, and ahead of countries such as Italy, Argentina, Germany, Australia, France, United Kingdom, United States, and Canada, while very similar to Japan and South Korea. Age-standardized YLD rRates for vision loss due to eye diseases 
declined between 1990 and 2015 with varying degrees in all-the 19 countries; except for that in China. 


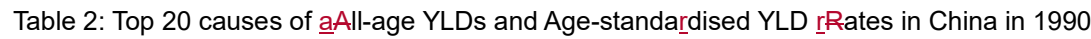
and 2015

\begin{tabular}{|c|c|c|c|c|c|c|c|c|c|c|}
\hline \multirow{2}{*}{ fause-name } & \multicolumn{2}{|c|}{$\begin{array}{l}\text { All Ages YLD } \\
\text { in } 1990\end{array}$} & \multicolumn{2}{|c|}{$\begin{array}{l}\text { All Ages YLD } \\
\text { in } 2015\end{array}$} & \multirow{2}{*}{$\begin{array}{l}\text { Percentage change } \\
\text { in All ages YLD } \\
\text { Aumber between } \\
1990 \text { and } 2015(\%)\end{array}$} & \multirow{2}{*}{$\begin{array}{c}\text { Age- } \\
\text { standardis } \\
\text { ed YLD } \\
\text { Rate in } \\
1990\end{array}$} & \multirow{2}{*}{$\begin{array}{c}\text { Age- } \\
\text { standardis } \\
\text { ed YLD } \\
\text { Rate in } \\
2015\end{array}$} & \multicolumn{2}{|c|}{$\begin{array}{l}\text { Percentage change } \\
\text { in Age-standardised }\end{array}$} & \\
\hline & $\begin{array}{c}\text { Total Numb } \\
\text { er }\end{array}$ & Rank & Number & Rank & & & & 1990 and & \multirow{2}{*}{\multicolumn{2}{|c|}{$\begin{array}{l}\text { Commented [NC3]: Again, I would do this in thousand. It } \\
\text { makes absolutely no sense to claim that you have the } \\
\text { accuracy to present this to } 8 \text { places! }\end{array}$}} \\
\hline Lower bakk pain & 6824391.5 & 1 & 10445627.6 & 1 & 53.1 & 696.0 & 655.8 & & & \\
\hline Neck pain & 4948621.3 & 3 & 9297530.8 & 2 & 87.9 & 514.9 & 556.1 & & 8.0 & \\
\hline $\begin{array}{l}\text { Age-related and other hearing } \\
\text { loss }\end{array}$ & 4784037.3 & 4 & 8555665.2 & 3 & 78.8 & 595.9 & 581.4 & & -2.4 & \\
\hline Major depressive disorder & 4565074.8 & 5 & 6681222.8 & 4 & 46.4 & 425.4 & 426.8 & & 0.3 & \\
\hline Diabetes mellitus & 2793655.8 & 10 & 5884165.5 & 5 & 110.6 & 307.0 & 360.6 & & 17.5 & \\
\hline $\begin{array}{l}\text { Other musculoskeletal } \\
\text { disorders }\end{array}$ & 3846366.6 & 6 & 5866966.2 & 6 & 52.5 & 361.7 & 371.3 & & 2.7 & \\
\hline Iron-deficiency anemia & 5615397.3 & 2 & 4829908.3 & 7 & -14.0 & 456.5 & 413.4 & & -9.4 & \\
\hline Schizophrenia & 2855975.1 & 9 & 4543735.7 & 8 & 59.1 & 262.9 & 274.1 & & 4.3 & \\
\hline Migraine & 3057968.1 & 8 & 4127002.9 & 9 & 35.0 & 265.6 & 265.6 & & 0.0 & \\
\hline Anxiety disorders & 3208267.9 & 7 & 3804590.5 & 10 & 18.6 & 276.6 & 267.3 & & -3.4 & \\
\hline $\begin{array}{l}\text { Vision loss due to eye } \\
\text { diseases }\end{array}$ & 2047612.3 & 12 & 3800391.3 & 11 & 85.6 & 241.4 & 257.8 & & 6.8 & \\
\hline Osteoarthritis & 1477761.2 & 14 & 3602698.2 & 12 & 143.8 & 190.0 & 218.5 & & 15.0 & \\
\hline $\begin{array}{l}\text { Chronic obstructive pulmonary } \\
\text { disease }\end{array}$ & 2634071.1 & 11 & 2772680.8 & 13 & 5.3 & 316.5 & 184.4 & & -41.7 & \\
\hline Dysthymia & 1435242.5 & 15 & 2300178.5 & 14 & 60.3 & 143.0 & 143.2 & & 0.1 & \\
\hline Drug use disorders & 1291166.0 & 16 & 2156146.9 & 15 & 67.0 & 100.6 & 142.8 & & 41.9 & \\
\hline Road injuries & 726933.0 & 23 & 1831072.7 & 16 & 151.9 & 74.2 & 114.8 & & 54.7 & \\
\hline Falls & 1056459.5 & 19 & 1606745.0 & 17 & 52.1 & 107.4 & 105.9 & & -1.4 & \\
\hline Food-borne trematodiases & 1237355.3 & 17 & 1527471.4 & 18 & 23.5 & 103.9 & 99.2 & & -4.5 & \\
\hline Bipolar disorder & 1074950.0 & 18 & 1410904.6 & 19 & 31.3 & 90.8 & 91.2 & & 0.4 & \\
\hline Alcohol use disorders & 929596.0 & 20 & 1363909.7 & 20 & 46.7 & 80.4 & 85.0 & & 5.7 & \\
\hline Ascariasis & 1891992.3 & 13 & 42722.1 & 29 & -97.7 & 164.4 & 3.0 & & -98.2 & \\
\hline
\end{tabular}

YLDs: years lived with disability

In 1990 and 2015, the burden from vision loss due to eye diseases ranked $12^{\text {th }}$ and $11^{\text {th }}$ respectively among all the causes ofthat can lead to health loss (Ttable 2 ). The rank of vision loss burden remained quite stable compared with burdens from other diseases in China. Most burdens from various causes increased in 2015 compared with those in 1990, except for Irondeficiency anemia and Ascariasis. Compareding with that in 1990, the All-age YLD total vision loss burden increased greatly in 2015 with percentage change as-increased by $85.6 \%$, the fifth-highest such increase-in All-age YLD Number between 1990 and 2015. The percentage change for it ranked $5^{\text {th }}$. The While-Age-standardised YLD rRate for the vision loss burden 
changed much less between 1990 and 2015, with the percentage change asincreasing by only $6.8 \%$, which was the $6^{\text {th }}$-highest increase. The range of percentage change in Agestandardised YLD Rate for top 20 causes was from $54.7 \%$ to $-98.2 \%$ between 1990 and 2015 , and the percentage change for vision loss burden ranked $6^{\text {th }}$ -
Formatted: Superscript 
Previous studies have usually focused on the prevalence of eye diseases alone to evaluate the burden of vision loss. Our study aimed to investigate the vision loss burden in China using both $\mathrm{p}$ Prevalence and YLDs, which enables the comparison of burden from vision loss with those from other diseases and in other countries. The results of our study can provide an overview understanding of vision loss burden in China for the first time.

OurThe findingsfesults indicated that by farthe burden of vision loss in China was dominated by Refraction and accommodation disorders, which is consistent with findings in other countries in the world. ${ }^{14-18}$ Considering that most Refraction and accommodation disorders can be safely and inexpensively corrected, greater efforts should be made to tackle this problem. 'VISION 2020: the Right to Sight' aims to eliminate avoidable blindness by the year 2020. Refraction and accommodation disorders mostly belong to avoidable blindness and should be considered as a priority have the priority to be taken care of. The second--leading cause of vision loss burden was Cataract, which is also the. Cataract was the leading cause for blindness in China. ${ }^{16,19}$ China's cataract surgery rate (CSR) in XXX was 1072/million/year, which was not only lower than those in developed countries, but also-lower than rates for other countries in the region with lower per capita incomes than China, includingthose in Thailand, Vietnam, Laos, Kampuchea, and the Philippines-and other developing countries. ${ }^{19}$ Tackling Cataract is still a great challenge in China, in part due to inadequate training opportunities for young surgeons.

Age-standardized pPrevalence $\underline{\text { rRates }}$ revealcan show the truereal burden of eye disease, $s$ excluding the effect of population size and age structure. For the past 25 years, aAgestandardized $\underline{p}$ Prevalence $\underline{r}$ Rates for Refraction and accommodation disorders, Cataract and Other vision loss almostremained virtually unchanged, which i particularly concerning, given that these conditions are eminently treatable. Of even greater concern is the fact thatlt was even worse that aAge-standardized PPrevalence RRates for Macular degeneration and Glaucoma actually gradually increased over this period. Little progress has been made in controlling the prevalence rate of these eye diseases. Due toCombined with population growth and aging, the aAll-age pPrevalences for all majorthe eye diseases in China havebeen dramatically increasing fromincreased dramatically between 1990 andto 2015, and willare predicted to increase untiltill 2020. Trachoma was the one exception, whose ageadjusted rate greatly decreased. China has made remarkable success in eradicating Trachoma. This is consistent with the fact that WHO has recently certified China free of active trachoma.

When we studied the vision loss burden by age group, it was encouraging that in population this fell between 1990 and 2015-agedin the 0 to -14--year group, it decreased from 1990 to 2015. But in the age groups above 15 years, the vision loss burden has increasedfor the past 25 years over this period, particularly among those. Especially above the age of 50 years, the burden substantially increased. Since the family planning policy began to take into effect from the beginning of 1970s and became one of China's basic state policies in 1982, significant 
attention has been paid to the children because of one-child only. The observed progress among younger ages may be due to China's one-child policy, promulgated since the 1970s, and the resulting attention paid by families to the well-being of children. Meanwhile, due in part to the one child policy, China has stepped into an aging population rapidly. China has made great efforts to control the population growth. Some experts predicted that in 2023 , the population will stop growing in China. ${ }^{20}$ But China has faced with severe population ageing and the situation will be more and more serious in the future. According to the classification criteria of the United Nations in 1956, when the number of people aged 60 years and over reaches $10 \%$ or the number of people aged 65 years and over reaches $7 \%$ of the population, the population is ageing. ${ }^{21}$ In 1990 , the population of China was over 1143 million, with $8.48 \%$ of the population were over 60 years old and $5.51 \%$ were over 65 years old ${ }^{20}$ But this policy has also led to the rapid aging of China's population, with the proportion aged 65 years and above growing from $5.51 \%$ in 1990 to In 2015, the population of China was over 1406 million, and $16.1 \%$ of the population was above 60 years old and $10.5 \%$ above 65 years oldin $\underline{2015} .{ }^{20}$ Most vision loss diseases-common causes of vision loss are age related, such as cataract, glaucoma and macular degeneration. The ageing population plays a significant impact on therole in the increasing burden of vision loss, and much more attention should be paid to population ageing. Nand national policy should give priority for the aged to control eye diseasesto controlling such eye diseases of aging.

The burden of vision loss in China was somewhat less than-a little better than that in India and was worse than those in other member countries of the G20. This was to be at was

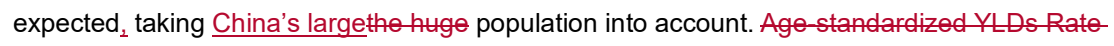
of vision loss burden in China ranked $10^{\text {th }}$-among the $G 20$ countries, higher than some developed countries and lower than some less developed countries. That is also acceptable. However, ilt is worth noting that China was the only country whose Aage-standardized YLD rRates for vision loss in 2015 was higher than that in 1990. Thisł is quite concerning assince it shows that there has been little was hardly any progression in controlling vision loss overfor the past 25 years. Without considering the population growth and ageing, the vision loss burden in China has not only failed to decrease, but increased. Thistt should serve as be a wakeup call for both the eyecare providers-eye doctors and healththe policy makers.

Comparing to 1990, the All-age YLDs from vision loss burden increased $85.6 \%$ in 2015 . Meanwhile, the Age-standardized YLDs Rate for it increased with percentage change of $6.8 \%$. It indicated that the difference of vision loss burden was majorly due to population growth and ageing and minorly due to less control of eye diseases. The burden of vision loss due to eye diseases ranked $12^{\text {th }}$ in 1990 and $11^{\text {th }}$ in 2015 among all the causes that can affect people's healthcauses of health loss in China. The real burden of vision loss mayight be even worse $_{2}$ - because as some diseases which also damage visual function and lead to blindness ${ }_{2}$ such as diabetic retinopathy, were not included in our study. For example, diabetic retinopathy was not evaluated separately in GBD 2015. Thus we could not investigate the vision loss burden from diabetic retinopathy. Furthermore, rarer causes of vision loss among children such as congenital cataract and, congenital glaucoma in Children have not been were not investigated in the GBD study. This tt is understandable ${ }_{2}$ since very few population-based 
studies have included younger age groups, thus it might bemaking it difficult to establish theprecise estimates. ${ }^{5}$ The burden of vAnd the vision loss couldmay be underestimatedstated due to the scarcity of data for because the data for children aged-younger than 15 years-aresearce. 2,5

This study has several limitations. Although the GBD Vision Loss Expert Group has tried theirbestmade every effort to collect all the published and unpublished data, ${ }^{5}$ the quantity and quality of data available are still limited, which. Differences in the quantity and quality of data entered into the system_could affect the accuracy of the estimated burden. However, it is persuasive that the data availability in China has similar levels to those in many developed countries. ${ }^{2,3,5} \mathrm{AlsO}_{2}$ the estimatedevaluation of vision loss burden in GBD 2015 might not be may be incomplete due to failure to include certain diseases, as noted above. Vision loss from several other diseases have not been included as described previously. The GBDstudies need some improvements. But it is by far Despite these limitations, GBD remains the most standardized and accurate system available to make comparisons, especially when we aim to-assess disease burdens across times and places, and across different diseases and injuries.

In summary, this study demonstrates that progress in controlling vision loss from eye disease in China has been sub-optimal over the last 25 years. quantitatively evaluated the burden of vision loss due to eye diseases in China. It is crucial to comprehend how well our health system was tackling these problems. It is particularly concerning that for the past 25 years, wad less control over the vision loss burden from eye diseases. In the future, China will face more serious population ageing as well as population growth and China willand should thus expectexpect a largerto encounter a growing burden of vision loss. Effective policies and measures to address this rising burden are of great priority for the goals of Vision 2020: The Right to Sights_- hould be a national priority. 


\section{References:}

1. National Bureau of Statistics of China. http://www.stats.gov.cn.

2. Gonghuan Yang, Yu Wang, Yixin Zeng. Rapid health transition in China, 1990-2010: findings from the Global Burden of Disease Study 2010. Lancet 2013;381:1987-2015.

3. Zhou M, Wang $\mathrm{H}$, Zhu J, et al. Cause-specific mortality for 240 causes in China during 1990-2013: a systematic subnational analysis for the Global Burden of Disease Study 2013. Lancet 2016;387:251-72.

4. Wang Y, Li X, Zhou M, et al. Under-5 mortality in 2851 Chinese counties, 1996-2012: a subnational assessment of achieving MDG 4 goals in China. Lancet 2016;387:273-83.

5. Stevens G, White R, Flaxman SR, et al. Global prevalence of visual impairment and blindness: magnitude and temporal trends, 1990-2010. Ophthalmology 2013;120:237784.

6. GBD 2015 Disease and Injury Incidence and Prevalence Collaborators. Global, regional, and national incidence, prevalence, and years lived with disability for 310 diseases and injuries, 1990-2015: a systematic analysis for the Global Burden of Disease Study 2015. Lancet 2016;388:1545-602.

7. Global Health Data Exchange. http://ghdx.healthdata.org.

8. Global Burden of Disease Study 2013 Collaborators. Global, regional, and national incidence, prevalence, and years lived with disability for 301 acute and chronic diseases and injuries in 188 countries, 1990-2013: a systematic analysis for the Global Burden of Disease Study 2013. Lancet 2015;386:743-800.

9. Vos T, Flaxman AD, Naghavi M, et al. Years lived with disability (YLDs) for 1160 sequelae of 289 diseases and injuries 1990-2010: a systematic analysis for the Global Burden of Disease Study 2010. Lancet 2012;380:2163-96.

10. Salomon JA, Vos T, Hogan DR, et al. Common values in assessing health outcomes from disease and injury: disability weights measurement study for the Global Burden of Disease Study 2010. Lancet 2012;380:2129-43.

11. Salomon JA, Haagsma JA, Davis A, et al. Disability weights for the Global Burden of Disease 2013 Study. Lancet Glob Health 2015;3:e712-23.

12. Murray CJL, Ezzati M, Flaxman AD, et al. GBD 2010: design, definitions, and metrics. Lancet 2012;380:2063-66.

13. Lindsay NB, Chante K, John H, et al. Global Burden of Eye and Vision Disease as Reflected in the Cochrane Database of Systematic Reviews. JAMA Ophthalmol 2015;133:25-31.

14. Pascolini D, Mariotti SP. Global estimates of visual impairment: 2010. Br J Ophthalmol 
2012;96:614-18.

15. Bourne RPA, Jonas JB, Flaxman SR, et al. Prevalence and causes of vision loss in highincome countries and in Eastern and Central Europe: 1990-2010. Br J Ophthalmol 2014;98:629-38.

16. Wong TY, Zheng Y, Jonas JB, et al. Prevalence and causes of vision loss in East Asia: 1990-2010. Br J Ophthalmol 2014;98:599-604.

17. Keeffe J, Taylor HR, Fotis K, et al. Prevalence and causes of vision loss in Southeast Asia and Oceania: 1990-2010. Br J Ophthalmol 2014;98:586-91.

18. Jonas JB, George R, Asokan R, et al. Prevalence and causes of vision loss in Central and South Asia: 1990-2010. Br J Ophthalmol 2014;98:592-8.

19. Zhao J. To improve the cataract surgery rate is a pressing matter of prevention of blindness in China. Chinese Journal of Medicine 2013;93:3729-30.

20. World Health Organization. World Health Statistics.

http://www.who.int/gho/publications/world_health_statistics/en/index.html

21. World Population Ageing:1950-2050. http://www.un.org/esa/population/publications. 